\title{
Results of non-microvascular flap cover surgery for management of soft tissue injury in open fractures of leg bones
}

\author{
Swayam Prakash Tripathy ${ }^{1}$, Mohammad Zuber ${ }^{2}$ Aanand Gautam ${ }^{3}$, \\ Arun Bhatnagar ${ }^{4}$,Suneet Tandon ${ }^{5}$, Sanjiv Gaur ${ }^{6}$ \\ ${ }^{I}$ (Department Of Orthopaedics, Gandhi Medical College,Bhopal, India) \\ ${ }^{2}$ (Department Of Orthopaedics, Gandhi Medical College,Bhopal, India) \\ ${ }^{3}$ (Department Of Plastic Surgery, Gandhi Medical College, Bhopal, India) \\ ${ }^{4}$ (Department Of Plastic Surgery, Gandhi Medical College, Bhopal, India) \\ ${ }^{5}$ (Department Of Orthopaedics, Gandhi Medical College,Bhopal, India) \\ ${ }^{6}$ (Department Of Orthopaedics, Gandhi Medical College,Bhopal, India)
}

\begin{abstract}
:
Background: The management of open Grade IIIB fractures of tibia requires aggressive debridement, fixation and early wound coverage by flap cover surgery.Raising non microvascular local and distant flaps require less expertise. We report a prospective trial to study the different types of flap coverage surgery used in leg and the various factors affecting the final outcome.

Materials \& Methods: 26 patients with open grade IIIB fractures of legs were managed by serial debridement and early fixation and flap coverage.The patients were followed and bony union and soft tissue coverage were observed.

Results: Patients who had undergone flap coverage within 7 days of injury had lesser duration of hospital stay, quicker unio, less complications and less number of bony and soft tissue procedures.

Conclusions: Open fractures of the leg should be managed with early flap coverage and rigid fixation.Majority of wounds may be managed with local and distant non-microvascular flaps.
\end{abstract}

Keywords: complications, early flap coverag, non- microvascular flaps, Open fractures , union

\section{Introduction}

Open fractures of tibia are more common than those of any other long bone because of very less soft tissue cover on the anteromedial surface ${ }^{[1]}$. The most important factor affecting the speed of union is the severity of initial trauma which is determined by the degree of displacement of fracture fragments and the extent of soft tissue injury ${ }^{[2]}$.

Often soft tissue coverage is not possible with primary closure or skin grafting as inadequate vascularity of the wound bed in this region prevents graft survival. In these cases flap coverage is the only option for bringing about adequate tissue coverage and promote bone healing.Early soft tissue coverage when combined with early fracture fixation would promote faster healing of bones and early return of function.

The purpose of our study was to study the different types of flap coverage surgeries used in leg and the various factors affecting the survival of the flap.

\section{Materials and methods}

Twenty six patients with open Gustillo \& Anderson Grade IIIB fractures ${ }^{[3]}$ of both leg bones(Tibia or/and fibula) were managed by local and distant flaps and various modalities of fixation(external fixation, plating , nailing) between September 2013 and January 2015 at Hamidia hospital, Bhopal.Thorough debridement of the wounds were done within six hours of admission. The wounds were reviewed after 48 hours and further debridement was done if considered necessary. Flap coverage was done in four to seven days.In case of infected wounds, further debridements were carried out and flap coverage was done after infection control. The patients included in our study were those with 1)Compound Grade III B fractures of the tibia or fibula or both2)Compound fractures of leg bones which were initially type I, II OR IIIA but later converted to Compound Grade IIIB because of skin necrosis or infection.We excluded patients who were managed by primary closure/skin grafting, those with vascular injury or those who had to undergo amputation primarily.We considered the radiological union score for tibia(RUST) and clinical criteria of painless weight bearing for assessing union ${ }^{[4]}$.For assessing flap the criteria used were turgor ,colour, temperature, margins (Healthy/ cyanosed /necrosed), bleeding on pin prick (bright red/bluish red), infection(+/-) ${ }^{[5]}$. 


\section{Results}

Our observations are given in the following tables

Sex distribution

\begin{tabular}{|l|l|l|l|l|}
\hline & Left & Right & & \\
\hline Sex & & & No.of patients & Percentage \\
\hline Males & 10 & 13 & 23 & 88.46 \\
\hline Females & 1 & 2 & 3 & 11.53 \\
\hline Total & 11 & 15 & 26 & 100 \\
\hline
\end{tabular}

Age distribution

\begin{tabular}{|l|l|l|}
\hline Age group(years) & Number of patients & Percentage $(\%)$ \\
\hline$</=10$ & 1 & 3.84 \\
\hline $11-20$ & 2 & 7.69 \\
\hline $21-30$ & 8 & 30.76 \\
\hline $31-40$ & 7 & 26.92 \\
\hline $41-50$ & 3 & 11.53 \\
\hline $51-60$ & 2 & 7.69 \\
\hline $61-70$ & 3 & 11.53 \\
\hline Total & 26 & 100 \\
\hline
\end{tabular}

Mode of trauma

\begin{tabular}{|l|l|l|}
\hline Mode of injury & Number of patients & Percentage(\%) \\
\hline Road Traffic accident & 21 & 80.07 \\
\hline Farm injury & 3 & 11.53 \\
\hline Assault & 2 & 8.4 \\
\hline Total & 26 & 100 \\
\hline
\end{tabular}

Distribution of patients according to the part of leg affected

\begin{tabular}{|l|l|l|}
\hline Part of leg & No. Of patients & Percentage \\
\hline Upper $1 / 3^{\text {rd }}$ & 6 & 23.08 \\
\hline Middle $1 / 3^{\text {rd }}$ & 14 & 53.84 \\
\hline Distal $1 / 3^{\text {rd }}$ & 6 & 23.08 \\
\hline Total & 26 & 100 \\
\hline
\end{tabular}

\section{Timing of flap}

\begin{tabular}{|l|l|l|}
\hline Timing of flap (days) & No. Of patients & Percentage(\%) \\
\hline $4-7$ & 10 & 38.46 \\
\hline $8-14$ & 4 & 15.38 \\
\hline $15-21$ & 7 & 26.93 \\
\hline$>22$ & 5 & 19.23 \\
\hline Total & 26 & 100 \\
\hline
\end{tabular}

Type of flap surgeries performed

\begin{tabular}{|c|c|c|c|}
\hline \multirow[t]{2}{*}{ Type of flap } & \multicolumn{2}{|c|}{ No. Of patients } & \multirow[t]{2}{*}{$\%$ of total flaps } \\
\hline & Primary flap & Secondary flap & \\
\hline \multicolumn{3}{|l|}{ Muscle/musculocutaneous flap } & 17.24 \\
\hline Gastrocnemius & 4 & & 13.79 \\
\hline Soleus & 1 & & 3.45 \\
\hline \multicolumn{3}{|l|}{ FASCIOCUTANEOUS FLAP } & 82.76 \\
\hline Ipsilateral superior based & 5 & & 17.24 \\
\hline Ipsilateral inferior based & 8 & & 30.76 \\
\hline Ipsilateral sural artery based & 4 & & 13.79 \\
\hline Bipediclled flap & 1 & & 3.45 \\
\hline
\end{tabular}


Results Of Non-Microvascular Flap Cover Surgery For Management Of Soft Tissue.....

\begin{tabular}{|l|l|l|l|}
\hline & & & \\
\hline Cross leg flap & 3 & 3 & 20.68 \\
\hline Total & 26 & 3 & 100 \\
\hline
\end{tabular}

Distribution of complications according to the timing of flap surgery

\begin{tabular}{|l|l|l|}
\hline & Early flap cover(</=7days) & Late flap cover(.>7days) \\
\hline Superficial infection & $2(20 \%)$ & $6(37.5 \%)$ \\
\hline Deep infection & $2(20 \%)$ & $5(31.25 \%)$ \\
\hline Partial necrosis & $1(10 \%)$ & $1(6.25 \%)($ \\
\hline Complete necrosis and flap loss & Nil & $2(12.5 \%)$ \\
\hline Non-union & Nil & $7(43.75 \%)$ \\
\hline Amputation & Nil & $3(18.75 \%)$ \\
\hline Total & 5 & 20 \\
\hline
\end{tabular}

Two patients had comorbid conditions in the form of left bundle branch block and Diabetis mellitus which led to complete flap necrosis due to decreased flap blood flow.

\begin{tabular}{|c|c|c|}
\hline \multicolumn{3}{|c|}{ Number of Secondary procedures } \\
\hline Secondary procedure & Early flap group & Late flap group \\
\hline Bone grafting & $1(10 \%)$ & $7(43.75 \%)$ \\
\hline Bone transport with illizarov & 0 & $4(25 \%)$ \\
\hline Bone marrow infiltration & 0 & $1(6.25 \%)$ \\
\hline Secondary flap & 0 & $3(18.75 \%)$ \\
\hline Implant removal & $3(30 \%)$ & 0 \\
\hline Renailing/Replating & $1(10 \%)$ & $1(6.25 \%)$ \\
\hline Secondary internal fixation & $1(10 \%)$ & $1(6.25 \%)$ \\
\hline Amputation & 0 & $3(18.75 \%)$ \\
\hline
\end{tabular}

Comparison for no. Of days of admission and time to union
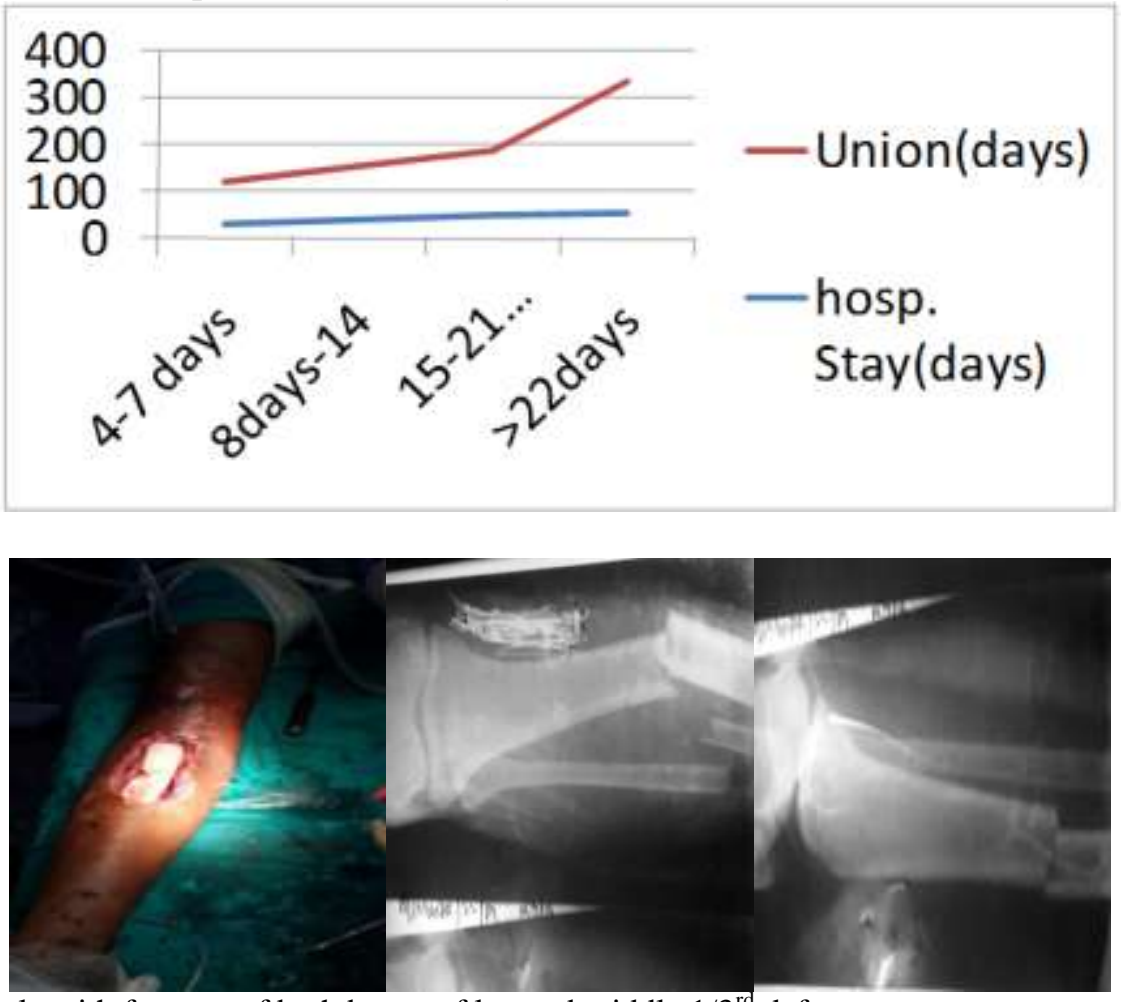

Pt.1-22 yr old male with fracture of both bones of leg and middle $1 / 3^{\text {rd }}$ defect 


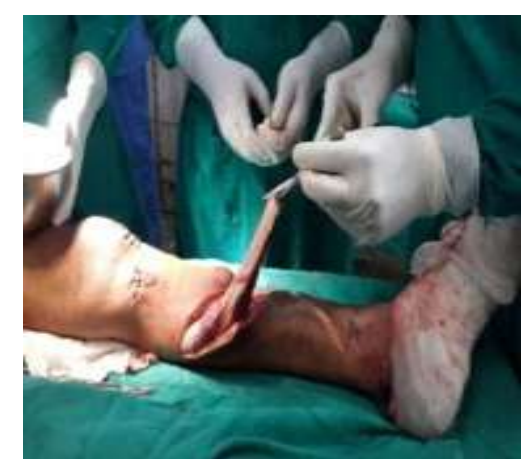

Gastrocnemius muscle flap and nailing

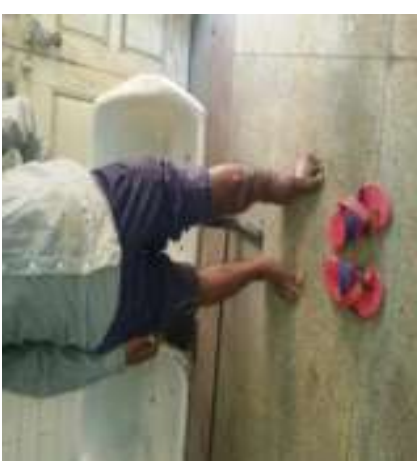

After union
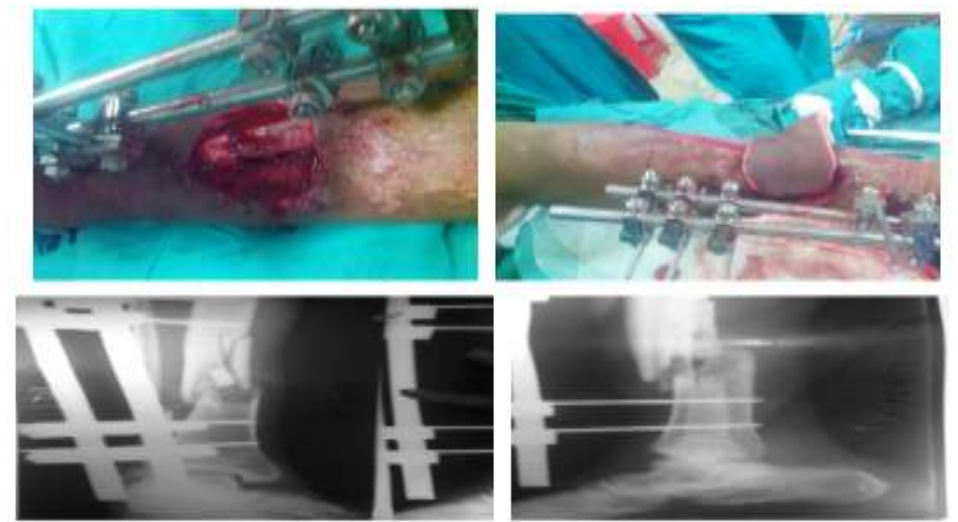

Pt. 2-36 yr old male with open fracture tibia and middle $1 / 3^{\text {rd }}$ defect Managed with inferiorly based fasciocutaneous flap and external fixation
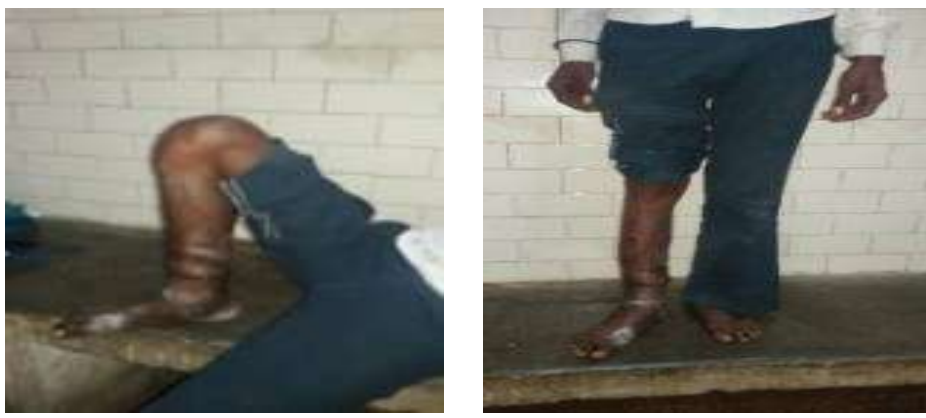

complete wound coverage and painless weight bearing

\section{Discussion}

In this era of high speed trauma,long bone fractures are a common occurrence. Tibia is one of the long bones which is commonly fractured and is frequently associated with open fractures.

The orthopaedic surgeon treating traumatic conditions can no longer isolate care of diaphysis of the long bones or the reconstruction of articular surfaces. He must also manage the tissue surrounding osseous structures and define a plan for soft tissues. The combination of soft tissue management and bone reconstruction permits optimal repair process to take place in both bone and soft tissue, avoiding the adverse sequel of failed implants, failed fixation, sepsis and ultimately amputation.( Levin Scott, 1993). ${ }^{[6]}$

A vast majority of our patients were males (88.46\%) in the age group of 20-40 years (Avg-36.12 years). Similar sex and age distribution of patients have been reported in previous studies by S.Gopal et al (2000) ${ }^{[7]}$, Chittora R et al(2004) ${ }^{[8]}$, S.Gopal et al (2004) ${ }^{[9]}$, Mahmood et al (2008) ${ }^{[10]}$, Jagannath Kamath et $\operatorname{al}(2012)^{[11]}$. 
Road traffic accident was the mode of trauma in most of the patients( $81 \%)$. In the study done by Chittora R and Mishra SM in 2004, most common mode of injury was crush injury(60\%) ${ }^{[8]}$. The road traffic accidents occured in 92 cases and 62 patients had polytrauma (more than three skeletal or nonskeletal associated injuries) in the study by Jagganath Kamath et al ${ }^{[11]}$. In our study the part of leg most commonly affected was the Middle $1 / 3^{\text {rd }}$ shaft $\left(53.84 \%\right.$ of patients).In the study by S.Gopal et al $(2000){ }^{[7]}$ and Mahmood A. Mahmood et al(2008) ${ }^{[10]}$ middle $1 / 3^{\text {rd }}$ defect was the most common.Chittora R and Mishra SM( 2004) ${ }^{[8]}$ and Jaggannath Kamath et al ${ }^{[11]}$, reported the lower $1 / 3^{\text {rd }}$ of leg as the most common site of wound .

$38.76 \%$ of our patients were operated with flap surgery and internal or external fixation within seven days of trauma while rest of them were operated after seven days. Jagganaath Kaamath et al.in their study suggested that soft tissue coverage should be done within five days of injury. ${ }^{[11]}$ In our centre immediate flap coverage was not possible because of non availability of plastic surgeons in emergency hours .

Fasciocutaneous flaps were the most commonly employed in our study.Gastrocnemius(13.79\% patients) muscle flap was the most commonly employed muscle flap while the inferiorly based flap $(30.76$ \%patients) was the most common fasciocutaneous flap.In the study by Chittora R et al. in 2004, all the 20 patients were managed by fasciocutaneous flaps out of which the inferiorly based fasciocutaneous flap was the most commonly used(65\% of patients). ${ }^{[8]}$ Mahmood et al in 2008 managed $33.3 \%$ patients with local fasiocutaneous flap, $50 \%$ with local muscle flap and $16.7 \%$ with free flap ${ }^{[10]}$.

Skin infection was the most common complication.Deep infection(osteomyelitis) was present in $26.92 \%$ patients, partial and complete flap necrosis were present in $7.69 \%$ patients each .Non union was seen in $26.92 \%$ patients while $11.53 \%$ patients had to undergo amputation.

Superficial infection was the most common complication in early and late flap groups.Deep infection was more common in late flap group.However more severe complications like complete flap necrosis, nonunion and amputation were seen exclusively in patients of the late flap group, being present in $12.5 \%, 43.75 \%$ and $18.75 \%$ of the patients.S.Gopal et al in 2000 reported a rate of infection of $6 \%$ in their study. ${ }^{[7]}$ In the late flap group, the rate of deep infection was $19 \%$ in their study while it was 3\% in the immediate flap group $(<24$ hrs).3.5\% patients had flap failure. Chittora R. et al in their study reported the incidence of wound infection, partial graft loss and partial flap necrosis as $10 \%, 10 \%$ and 5\% respectively. ${ }^{[8]}$ Mahmood et al in 2008 reported the incidence of flap infection, non union, flap necrosis and osteomyelitis respectively as $16.6 \%$ each in the early flap group.In the late flap group, these complication were $55.5 \%, 33.3 \%, 22.2 \%$ and $33.3 \%$ respectively. [10]

More number of patients in the late flap group had to undergo secondary bony or soft tissue procedures in our study.In the early flap group ten percent of the patients had to undergo bone grafting, $30 \%$ underwent implant removal, ten percent renailing or replating and $10 \%$ underwent secondary internal fixation.In the late flap group, the percentage of patients who underwent bone grafting was $43.75 \% .18 .75 \%$ patients had to undergo amputation because of infected non union or failure of soft tissue reconstruction . 25\% underwent bone transport with illizarov, $6.25 \%$ bone marrow infiltration, $18.75 \%$ secondary flap.Renailing and secondary internal fixation was done in $12.5 \%$ of the patients.S.Gopal in 2000 reported two patients in each of the two groups who underwent amputation.Secondary flap was done in two patients. three patients were treated with bone transport. ${ }^{[7]}$

Average number of days of admission in case of patients managed with early flap cover surgery was 33.2 days while for the late flap group it was 51.62 days.The average time to union was 18.4 weeks while for the late flap group it was 45.64 weeks. S.Gopal et al in 2004 reported mean union time of 34.85 weeks.In case of patients operated within $72 \mathrm{hrs}$ it was 31.84 weeks. ${ }^{[9]}$

In our study the failure rate is higher in case of muscle flap.This is because of less number of cases in our study.However other studies by Mahmood etal ${ }^{[10]}$, and Hallock ,Geoffrey et al ${ }^{[12]}$ has shown lesser complications in case of muscle flaps as muscle flaps had an important roll in eliminating the dead space potentiality for infection and enhance the immunologic milieu by improving the vascularity and oxygen delivery to the contaminated wound.

We recommend the Gastrocnemius muscle flap or the superiorly based fasciocutaneous flap for upper $1 / 3^{\text {rd }}$ defects.This is supported by previous studies by Jaggannath Kamath et al ${ }^{[11]}$, Mahmood A. Mahmood et al ${ }^{[10]}$ and R.Hertel ${ }^{[13]}$.In case of middle $1 / 3^{\text {rd }}$ defects we have used the proximally or distally based fasciocutaneous flaps from anterior -lateral or posterior- medial compartments.Also a soleus muscle flap may be used if dead space is present.In case of distal $1 / 3^{\text {rd }}$ defects, we have used sural artery based flaps and cross-leg flaps. This is as per the recommendations made by Jaggannath Kamath et al ${ }^{[11]}$ and Andrew N. Et al ${ }^{[14]}$.

The complications were higher in wounds larger in size.Although cross leg flaps have survived and have brought about wound coverage, but the severe complications like osteomyelitis and infected non -union ultimately leading to amputations were higher in these cases.Thus attempts at salvaging limbs with already infected wounds greater than $15 \mathrm{cms}$ size has often led to prolonged treatment leading to loss of function.Since most of our patients are poor, amputation was preffered after deep infection rather than further attempts at limb 
salvage. Also two of our patients had impaired circulation because of left bundle branch block and diabetes mellitus which led to complete flap necrosis.Hence any factor which impairs the local circulation, should be corrected first.

\section{Conclusion}

All compound fractures should be managed by thorough debridement , preferably within six hours and then after 48 hours if found necessary.Soft tissue coverage should be done as early as possible, preferably in four to seven days.Centres which do not have facilities for flap coverage should refer patients to tertiary care centres as eary as possible as early reconstruction has lower percentage of complications .Also considering the economic implications of prolonged attempts at limb salvage in case of large contaminated wounds, amputation may be considered.This is supported by previous studies by Sarmiento et al . We have found the local and regional flaps to be appropriate in bringing about soft tissue coverage and thus avoid microvascular free flaps.Any factor which compromises the survival of flap ( e.g anaemia, diabetes mellitus, hypodynamic circulation, smoking etc.) should be corrected first.

\section{References}

[1]. Matthew L.Rudloff:Fractures of the lower extremity; Campbell's operative orthopaedics,vol.III,12,2644

[2]. H.Ellis:The speed of healing after fracture of the tibial shaft;The Journal of Bone and Joint Surgery-1958 Nov;40(B) 42-46

[3]. Gustillo R.B , Anderson J.T:Prevention of infection in the treatment of one thousand and twenty five open fractures of long bones:retrospective and prospective analysis, J Bone and Joint Surgery Am. 1976;58:453-458

[4]. Brian M. Parrett, Julian J. Pribaz:Lower extremity reconstruction; Rev. Med. Clin. Condes-2010; 21 (1) 66-75

[5]. Saam Morshed:Current options for determining fracture union;Advances in Medicines; 2014 ; Volume.20:311-16

[6]. Levin Scott:Compound fractures of lower extremity;Trauma;1993-may;64(3):1122-1128

[7]. Gopal S. , Majumdar S., Batchelor A.G.B , Knight S.L et al:J Bone and Joint surgery [Br] 2000; 82-B:959-66

[8]. Chittora R., Mishra S.M:Fasciocutaneous flaps in reconstruction of lower extremity., our experience;Kathmandu University Medical Journal 2004; Vol. 2, No.4

[9]. S.Gopal,P. V. Giannoudis,A.Murray,S.J Mathews,R.M. Smith:The functional outcome of severe open tibial fractures managed with early fixation and flap coverage;JBJS;2004-August;86(B):861-67

[10]. F M.A Mahmood. Ali Khudair,Zuhair Fatallah:Soft Tissue Reconstruction in Severe Open Leg Fractures(Gustillo Type III);Basrah Journal of Surgery 2008-Sept.14;66-75

[11]. Jagannath B Kamath, M Shantaram Shetty, Thangam Verghese Joshua1, Ajith Kumar, Harshvardhan, Deepak M Naik: Soft tissue coverage in open fractures of tibia;Indian Journal of orthopaedics; 2015-November,46(4).218.240

[12]. Hallock, Geoffrey G. MD.Utility of both muscle and fascia flaps in severe lower extremity trauma, Journal of trauma, injury, critical care 2000; Volume48(5),pp 913-917

[13]. R. Hertel. M.D:Standard Regional Flaps for soft tissue coverage of the leg: Techniques in orthopaedics; (2), Lippincott-Raven Publishers ;Philadelphia- 1995,14:122-123

[14]. Andrew N. Pollak, ; Melissa L. McCarthy; Andrew R. Burgess: Short-Term Wound Complications After Application of Flaps for Coverage of Traumatic Soft-Tissue Defects About the Tibia; J Bone Joint Surg Am, 2000 Dec; 82 (12): 1681 -1686 